\title{
TECH TRANSFER BRIEFING \\ Federal-state partnership yields success in remote sensing analysis of conservation practice effectiveness: Results from the Choptank River Conservation Effects Assessment Project
}

doi:10.2489/jswc.64.5.154A

\author{
W. Dean Hively, Gregory W. McCarty, and Jason Keppler
}

$\mathrm{n}$ the modern era of ecosystems management, considerable focus has been placed on implementing agricultural conservation practices to protect water quality. As a result, farmers are shouldering the responsibility for managing land and nutrient resources in a sustainable manner, despite the inherent nutrient inefficiencies associated with modern high-input cropping systems. To aid them, state and federal resources have been devoted to cost-share programs supporting implementation of agricultural best management practices. The question that naturally arises is, What are the actual conservation effects of these practices, given variability in farm management, landscape, and climate? Remote sensing data can help to answer this question by providing rapid measurement of vegetation dynamics associated with conservation practice implementation in the real-world landscape. When combined with site-specific agronomic information derived from environmental cost-share program enrollment records, satellite imagery analysis can provide a powerful tool for evaluating conservation practice effects, providing information for adapting future iterations of cost-share program implementation to promote the most effective and sustainable management practices.

In the Chesapeake Bay watersheds, the use of winter cover crops has been identified as an important conservation practice for reducing nutrient and sediment losses from farmland. Planting nonleguminous cover crops (rye, barley, and wheat) following the harvest of summer row-crops (corn, soy, and vegetables) can capture residual soil nitrate nitrogen $(\mathrm{N})$ that would otherwise leach to groundwater over the winter. Cover crop success, however, requires early planting, good management, and favorable climate. Scientists at the USDA Agricultural Research Service have partnered with the Maryland Department of Agriculture to evaluate cover crop performance in the Choptank River watershed, on Maryland's Eastern Shore. This ongoing federal-state collaboration has developed during four years of research activities associated with the Choptank River Conservation Effects
Assessment Project. Support for the project has also come from three Chesapeake Bay Program watershed grants administered by the National Fish and Wildlife Foundation.

Each year, cost-share program enrollment records are used to identify and locate all cover crop fields located within the study area and to provide agronomic management information for each field. Satellite imagery is acquired in late December, to measure cover crop biomass prior to the onset of winter, and again in March, to measure springtime biomass. Simultaneously, approximately 30 fields are hand-sampled by Agricultural Research Service scientists to gather data for converting satellite reflectance measurements to estimates of biomass and nutrient uptake. In this manner, aboveground biomass and $\mathrm{N}$ uptake estimates can be calculated for all fields enrolled in the cover crop program. Associated agronomic information (species planted, planting date, planting method, and previous crop) can then be used to parse out the effects of management strategies on cover crop performance. In addition, actual conservation program dollars spent per pound of $\mathrm{N}$ sequestration can be calculated on county, watershed, and regional bases. Results from the first year of analysis (2005 to 2006), presented in a full paper on pages 303 to 313 of this issue (Hively et al. 2009), show that actual on-farm cover crop performance was considerably less than that observed in plotscale research. This was largely due to the choice of underperforming species (wheat), along with late planting dates, climate effects, and suboptimal planting methods.

Currently, the project is entering a phase of technology transfer. In the coming year, a pilot project will be started in the Talbot County, Maryland, Soil Conservation District. A geospatial data capture tool will be programmed to streamline the collection of agronomic data from farmers during the cost-share program enrollment period. These data will be linked to geospatial field boundaries, allowing a comprehensive satellite analysis of cover crop productivity on all fields within the county. This will lead to the calculation of county and watershed totals for factors such as enrollment acreage, bio-

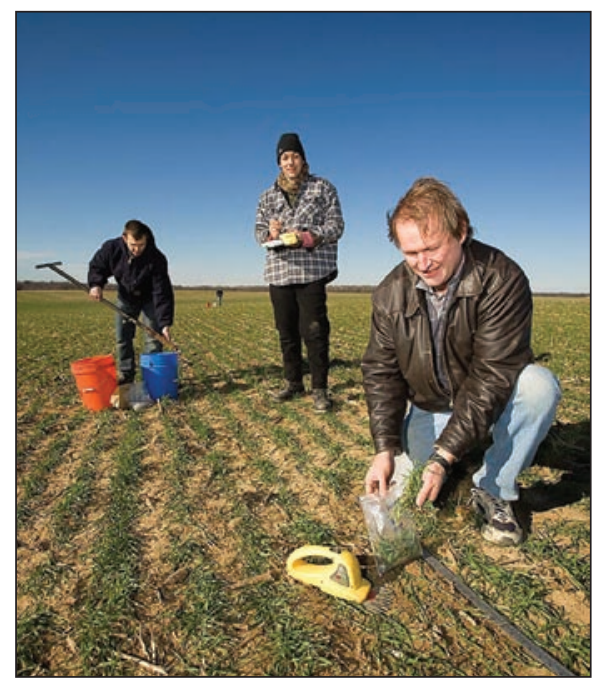

Sampling plant biomass and soil nitrogen on a cover crop field in the Choptank River watershed, Maryland (From right to left: Gregory McCarty, Dean Hively, Megan Lang [USDA ARS], and Trevor Mitchell [Maryland Department of Agriculture]). Photo credit: Stephen Ausmus, USDA ARS Agricultural Research magazine.

mass accumulation, nutrient uptake, and cost per pound of nitrogen sequestration. Every participating farmer will receive a fieldby-field report of cover crop performance, along with information on countywide performance totals and supplementary information promoting adoption of the most successful cover cropping strategies. Additionally, underperforming fields can be evaluated by Soil Conservation District field staff to identify causes of cover crop failure, and farmers can be engaged in discussion of strategies for improving cover crop performance in coming years. It is hoped that this combined strategy will increase winter cover crop effectiveness in the agricultural landscape. As the project progresses, the impacts of adaptive management on the performance of winter cover crops can be measured and tracked on an ongoing basis.

For further information see the full paper on pages 303 to 313 of this issue (Hively et al. 2009).

\section{REFERENCES}

Hively, W.D., M. Lang, G.W. McCarty, J. Keppler, A. Sadeghi, and L.L. McConnell. 2009. Using satellite remote sensing to estimate winter cover crop nutrient uptake efficiency. Journal of Soil and Water Conservation 64(5):303-313. 